\title{
Assessment of emergency supply of healthcare facilities as a module of the crisis management information system
}

\author{
Katerina Vichova ${ }^{1, *}$, Martin Hromada ${ }^{1}$ \\ ${ }^{1}$ Tomas Bata University in Zlín, Faculty of Applied Informatics, Department of Security Engineering, Nad Stráněmi 4511, 76005 Zlín, \\ Czech Republic
}

\begin{abstract}
This paper focuses on assessing the crisis preparedness of healthcare facilities as a new module of crisis management information systems. The crisis is widespread around the world, and it is essential that the medical facility is ready. The first part of the thesis deals with the introduction to the given issue and the crisis preparedness of the population. The second part of the paper deals with the analysis of extraordinary events and crisis situations around the world. The impact of emergencies on healthcare facilities is described in this part. The third part of the thesis deals with the emergency survival of the population. The following part describes the methods used in this research. The heuristic analysis of preparedness is one of the most valuable methods. The next section presents the results of the work according to the chosen method. In this section, we will find the strengths and weaknesses of the evaluated medical facilities. At the end of the thesis is proposed a new module for evaluation of medical facilities. This module can be applied as part of crisis management information systems.
\end{abstract}

\section{Introduction}

Each of us will encounter some emergencies or crisis in his life. These situations come to our lives unexpectedly and cause loss of life, health, and property of citizens. Natural disasters that originated from extreme weather events have been in an increasing trend in recent years. [1] These incidents also affect medical facilities that have to provide health care to citizens located in this facility. Crisis team management focuses on team performance skills during an emergent situation that occurs when a patient has a clinical event that requires immediate intervention. Team work during a crisis situation impacts outcome no matter the setting. [2, 3] In times of emergencies or crisis, supplies may be interrupted. It can be caused by the many situations which are described in the next part of the paper. In the Czech Republic, this can happen especially in storms, snow calamities or floods. Abroad, for example in coastal states, it can cause typhoons, hurricanes or snowstorms. Hurricane Sandy, the largest hurricane in the 2012 Atlantic hurricane season and the second costliest natural disaster in the U.S. history. [4] Numerous governmental and non-governmental agents worked together and responded to the disaster. In addition to physical supports, timely and updated information serves as an intangible help, which can reduce uncertainty and fear, and contribute to timely decisions for more efficient evacuations and reliefs. [5]

The central principle that defines a new perspective on the current state of health in its role in ensuring the security of individual citizens and the state is the duty of the country to save life and prevent serious health injuries for all disabled people in various types of emergency, consequences of the terrorist use of chemical, biological, radiological or nuclear means. [6]

To meet the expectations of the population of the Czech Republic over health care capacity the fundamental human right to save life and health, even in extraordinary circumstances, is in the security environment defined in the Czech Republic's Security Strategy, the most significant a description of the strategic goal of creating a coherent and mainly functional "health system rescue". [6]

The Charter of Fundamental Rights and Freedoms in the Czech Republic states: "Everyone has the right to health protection. Citizens have the right to free healthcare and healthcare by public insurance under the conditions laid down by the law". [7] This right of citizens also applies when a state of crisis is declared, or an extraordinary event occurs too. It is, therefore, necessary for the healthcare facility to be able to provide food, drinking water and energy for people in the healthcare facility.

Safeguarding emergency survival measures is a summary of the activities and practices of the relevant bodies, other stakeholders and the citizens themselves, the aim is conducted to minimize the negative impact of emergencies and crisis on the health and lives of the affected population. [8]

The obligation to provide health care depends on the emergency preparedness of the hospital. As has been said, every hospital must be prepared to face extraordinary events and crisis. This is called the concept

\footnotetext{
"Corresponding author: kvichova@utb.cz
} 
of crisis preparedness of hospitals. This term is used in the Czech Republic and Europe. Some other states also use different terms for this activity. The term mass casualty incident is particularly used in literature from the United States of America. [9]

Under Act No. 239/2000 Coll. about a joint rescue system defines the basic concepts. Protection of the population is the fulfilment of civil protection tasks, especially warnings, evacuations, hiding and emergency survival of the population and other measures to ensure the protection of its life, health, and property. Further, $\S$ 10 sets out the tasks of the Region, according to which the Fire Rescue Service performs rescue and liquidation work and also organizes and coordinates evacuation, emergency accommodation, emergency drinking water supplies, food and other necessary means of survival of the population. [10]

The following figure shows a summary of measures to protect the population. As mentioned, one of the criteria is emergency survival. It must also be provided to persons present at an emergency in healthcare facilities.

As mentioned, one of the measures is emergency survival. It must also be ensured for persons present at an emergency in healthcare facilities

Crisis management information systems are made up of many modules. These are used to handle emergencies or crisis. No module has yet been put in place to assess healthcare facilities regarding their preparedness to face emergencies or crisis. The purpose of this article is to present the assessment criteria for healthcare facilities for emergency supply.

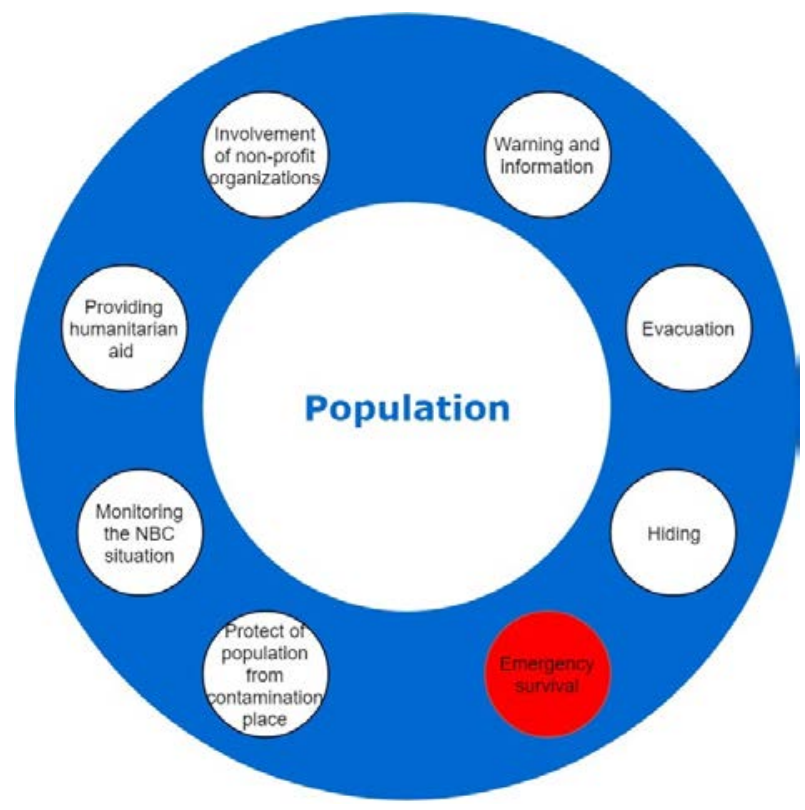

Fig. 1. The measures to protect the population $[11+$ author editing].

\section{Analysis of Selected Emergencies and Crisis}

The aim of this chapter is to present emergencies that have disrupted supplies of food, food, water for the survival of the population. In such cases, there are measures for the emergency survival of the population. These measures are necessary to overcome an emergency.

In the world, the primary deliveries to the survival of the population are the most often caused by the movement of the air mass - the storm and the hurricane. This has the effect of interrupting energy supplies. This is one of the defined measures of emergency population survival.

\section{The United States of America}

Hurricane Sandy struck off the US coast in October 2012. It was a post-tropical cyclone. Hurricane began as a tropical wave in the Caribbean and quickly changed into a tropical storm in just 6 hours. It was transformed into a hurricane on October 24 . The total deaths reached 285 , including 125 deaths in the United States. Hurricane caused 62 billion dollars of damage and 315 million dollars in the Caribbean. New York was the most affected due to injury to subways and road tunnels. More than 7.5 million people were without electricity [12].

Hurricane Sandy in New York will cause floods in hospitals. That caused power outages. Five hospitals were forced to evacuate. The evacuation was also due to aggregate outages. Other hospitals were evacuated due to flooding of cellars. Aggregates that stopped working here were placed here. The army helped the evacuation. Other include Hurricane Irma. It was the most powerful hurricane of the Atlantic in recorded history. The storm arrived on the coast of Barbuda in September 2017. Its wind was 185 miles per hour for 37 hours. More than 10 million of the population remained in Florida without electricity. More than 5 million Florida residents were evacuated. [13]

Hospital was affected by the hurricane Irma too. They chose to dismiss patients who were able to be in home care. Other patients had to be evacuated to other hospitals. In some hospitals, urgent income was also interrupted.

The United States suffers from hurricanes of varying degrees. Other significant storms include Bob (1991), Dennis (2005), Katrina (2005), Gustav (2008), Issac (2012), Arthur (2014), Mathew (2016), Nate 2017).

\section{Europe and the Czech Republic}

In 2007, the orc Kyrill drove over Europe. In three days, he demanded 48 victims. This orc was overflowing across Britain, Germany, the Netherlands, Poland, the Czech Republic.

In the Czech Republic, power outages occur most often due to storms. It is possible to remember the orc Kyrill, who in 2007 hit the whole of the Czech Republic. This gauntlet resulted in four human sacrifices and caused billions of damage [14].

The same storm struck Herward 10 years later (2017).

In December 2011, the hurricane Dagmar hit the coast of Norway. It was called "thousand-year storm" that reached far into the country and caused massive tree falls over the power lines. 1.3 million citizens lost their electricity supply, 14.000 for more than 48 hours [15].

In December 2013, the hurricane Ivar caused a blackout for 60.000 citizens in the north of Sweden due 
to extensive tree falls. While the majority of the affected household got their electricity back within 24 hours, over 1,000 household were without electricity for more than 5 days.

Similar to Dagmar in both strength and extent of damage, Ivar took out critical infrastructure including roads, trains, electricity, and telecommunication [15].

\section{Emergencies Holding of Healthcare Facilities}

In the times of an emergency or a crisis and a disruption of supply, there are measures for the emergency survival of the population. The illustration below shows necessary supplies for emergency survival.

Figure 2 presents necessary measures that are required for the emergency use of the population. In particular, it is an emergency supply of water, food, and energy. These supplies are crucial in emergencies or crisis that may affect health care facilities [8].

There may also be emergency accommodation, necessary emergency services and the organization of humanitarian aid. It should be noted. However, that evacuation of the entire hospital, such as the county hospital, cannot be carried out. If there was a crisis - a flood and the buildings of a health care facility were at risk, it would be sufficient to evacuate only within the building. It is, therefore, necessary for patients to evacuate from the ground floor of the building to the upper floors, along with the staff and the appropriate devices.

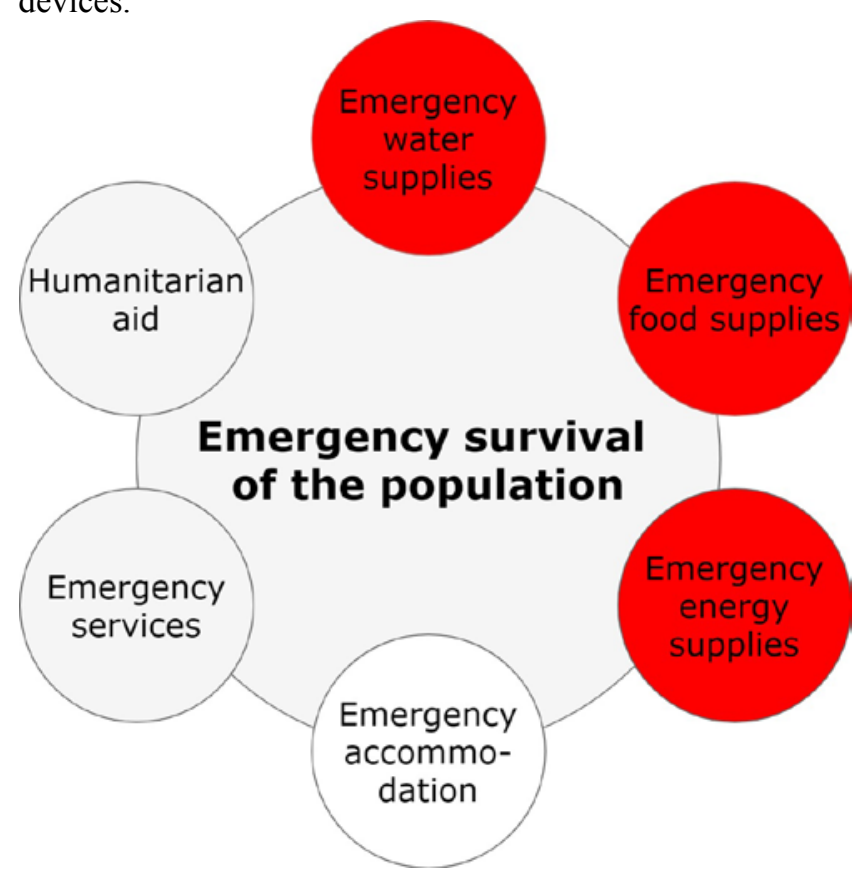

Fig. 2. Emergency survival of the population [author].

However, it is necessary to take into account the situation where, in the event of a crisis - the floods will flood part of the building, it is assumed that there may be power outages. For these situations, hospitals are equipped with power generators that can provide energy for a specified period.

\section{Methodology}

Four methods of scientific work were used in this article. The method of analysis is used because it uses the principles of logic to achieve the set goal and provide the framework to explore the principles of crisis management and crisis preparedness of the healthcare facilities. The induction method was used, where this method serves to examine the fact of creating a hypothesis from the points obtained. Comparison method allows to evaluate and analyse processes and approaches in healthcare facilities in the Czech Republic. Finally, heuristic analysis of preparedness was used.

A heuristic analysis of preparedness was developed for the evaluation of healthcare facilities. This method is based on a quantitative assessment of the availability of emergency medical facilities. Based on this assessment, we will get an accurate idea of the weaknesses and strengths of the assessed healthcare facilities.

The evaluation of the system used a set of evaluation questions, which was divided into five categories. As mentioned above, we propose a system for assessing healthcare facilities from an emergency supply point of view, focusing on three measures - emergency water supplies, emergency food supplies and emergency supplies.

Emergency Water Supply - this category aims to evaluate whether the hospital is prepared for water loss drinking or utility. It is assessed how long the hospital can withstand its water supplies. It is also evaluated whether the hospital has a contract with the supplier of drinking water - packaged, in a tanker. It is also necessary to assess the area of service water that is necessary for the operation of the medical facility. In the last part, the dry toilets are evaluated at the time of the loss of utility water.

Emergency Food Supply - this category evaluates whether a cookery shop is being built in a health facility. In the event of a food supply failure, it is assessed whether the hospital has a supply of food. It is also evaluated whether the hospitals are contractually contracted by hot food suppliers, food supplies or finished meals.

Emergency Power Supply - this category evaluates the preparedness of the healthcare facility for emergency energy supplies - the ownership of energy supply replacement units. However, these aggregates are fueldependent, and it is, therefore, necessary to assess fuel supply to the hospital. It deals with the area of contractual fuelling, its gas station, etc.

Other Emergency Supply - this category only marginally identifies the supply of medical equipment from supply of drugs, blood and blood plasma and their contractual provision.

Hospital Capacity - this category addresses the current capacity of the health facility. The availability of free beds, medical staff, hospitalized is evaluated. Also, it is essential to deal with their distribution (children/adults, diets, acute).

Based on the above analysis, an evaluation was performed using the following formula: 


$$
H F P=((R+H) / 2 \times R) \times 100 \%
$$

Where, HFP = healthcare facility preparedness, $\mathrm{R}=$ sum of results (obtained points), $\mathrm{H}=$ number of assessed heuristics.

The evaluation methodology consisted in assigning a response to each question answered in the form of valuation from a predefined set of values $(0=$ does not meet; 1 = meets; blank field if the problem is not relevant).

\section{Results}

In the article of the work, three medical facilities of the Regional Hospital and the Faculty Hospital were evaluated.

The proposed method was used to assess the medical facility. Firstly, there was evaluated healthcare facilities, type hospital of municipality.

Table 1. Heuristic analysis of preparedness - hospital of municipality [author].

\begin{tabular}{|c|c|c|c|c|}
\hline Category & Qusestins & Answers & Points & Total \\
\hline Water & 9 & 9 & 6 & $83.33 \%$ \\
\hline Food & 11 & 11 & 8 & $86.36 \%$ \\
\hline Energy & 9 & 9 & 6 & $83.33 \%$ \\
\hline Others & 6 & 6 & 5 & $91.67 \%$ \\
\hline Capacity & 8 & 8 & 0 & $50 \%$ \\
\hline Total & 43 & 43 & 25 & $78.94 \%$ \\
\hline
\end{tabular}

Table 1 shows the results of the heuristic analysis of hospital preparedness - hospital of municipality. As can be seen, the best-assessed category is preparedness others types supply (accommodation, blood, medical supplies). The overall preparedness of the hospital is $78.94 \%$.

Secondly, there was evaluated healthcare facilities, type regional hospital.

Table 2. Heuristic analysis of preparedness - regional hospital [author].

\begin{tabular}{|c|c|c|c|c|}
\hline Category & Questins & Answers & Points & Total \\
\hline Water & 9 & 6 & -2 & $33.34 \%$ \\
\hline Food & 11 & 9 & -2 & $38.89 \%$ \\
\hline Energy & 9 & 8 & 1 & $56.25 \%$ \\
\hline Others & 7 & 7 & 3 & $71.43 \%$ \\
\hline Capacity & 8 & 8 & 8 & $100 \%$ \\
\hline Total & 44 & 38 & 8 & $59.98 \%$ \\
\hline
\end{tabular}

Table 2 shows the results of the heuristic analysis of hospital preparedness - regional hospital. As can be seen, the best-assessed category are capacity of the hospital. The overall preparedness of the hospital is $59.98 \%$.
Table 3. Heuristic analysis of preparedness - faculty hospital [author].

\begin{tabular}{|c|c|c|c|c|}
\hline Category & Questions & Answers & Points & Total \\
\hline Water & 9 & 9 & 7 & $88.89 \%$ \\
\hline Food & 11 & 11 & 7 & $81.81 \%$ \\
\hline Energy & 9 & 9 & 8 & $94.45 \%$ \\
\hline Others & 6 & 6 & 5 & $91.67 \%$ \\
\hline Capacity & 8 & 8 & 6 & $87.5 \%$ \\
\hline Total & 43 & 43 & 33 & $88.87 \%$ \\
\hline
\end{tabular}

Table 3 shows the results of the heuristic analysis of hospital preparedness - faculty hospital. As can be seen, the best-assessed category is preparedness others types supply (accommodation, blood, medical supplies). The overall preparedness of the hospital is $88.87 \%$.

The heuristic analysis of preparedness was used by the three hospitals (different types). The best-assessed was faculty hospital. Secondly, it was hospital of the municipality. Finally, the worst assessed was regional hospital.

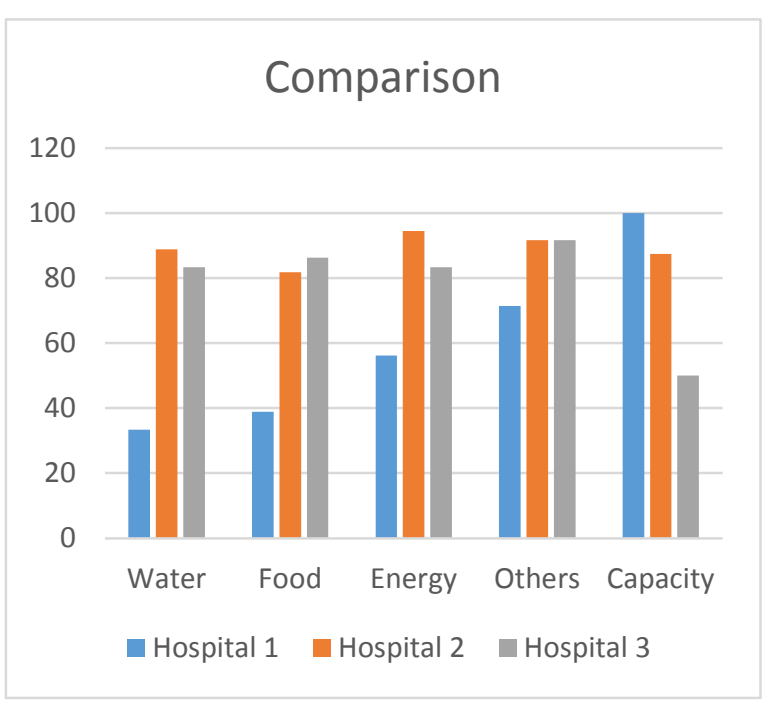

Fig. 3. Comparison oh hospital preparedness [author].

Figure 3 shows the comparison of the hospital preparedness. The best-assessed was faculty hospital. Secondly, it was the hospital of the municipality. Finally, the worst assessed was the regional hospital.

Table 4. Strengths and weaknesses of the analysed hospital [author].

\begin{tabular}{|c|c|}
\hline Strengths & Weaknesess \\
\hline \multicolumn{2}{|c|}{ Hospital 1 - hospital of municipality } \\
\hline $\begin{array}{l}\text { Stocks of bottled drinking } \\
\text { water. }\end{array}$ & $\begin{array}{l}\text { There is no online number } \\
\text { of hospitalized patients. }\end{array}$ \\
\hline $\begin{array}{l}\text { Contractual supply of } \\
\text { drinking water. }\end{array}$ & $\begin{array}{l}\text { There is no online number } \\
\text { of medical staff available. }\end{array}$ \\
\hline $\begin{array}{l}\text { Contractualsupply of } \\
\text { food. }\end{array}$ & \\
\hline $\begin{array}{l}\text { Contractual supply of } \\
\text { medication and blood. }\end{array}$ & \\
\hline Contractual supply of fuel. & \\
\hline $\begin{array}{l}\text { Contractual supply of dry } \\
\text { toilets. }\end{array}$ & \\
\hline
\end{tabular}




\begin{tabular}{|c|c|}
\hline \multicolumn{2}{|l|}{ Own kitchen. } \\
\hline \multicolumn{2}{|l|}{ Hospital 2 - regional hospital } \\
\hline $\begin{array}{l}\text { The quality of drinking } \\
\text { water is controlled. } \\
\text { Own grocery store with } \\
\text { food stock. } \\
\text { Stocks of raw materials } \\
\text { for nutrition for two days. } \\
\text { The preparedness for } \\
\text { power failure - aggregate. } \\
\text { Stocks of fuel to the } \\
\text { aggregate in } 12 \text { hours. } \\
\text { The stocks of medicines, } \\
\text { blood, blood plasma and } \\
\text { medical supplies. } \\
\text { Online capacity for the } \\
\text { number of patients and } \\
\text { staff. }\end{array}$ & $\begin{array}{l}\text { There are no supplies of } \\
\text { bottled drinking water for } \\
\text { patients. } \\
\text { There is no contract of } \\
\text { supplies of bottled } \\
\text { drinking water. } \\
\text { There is no contract to } \\
\text { deliver dry toilets. } \\
\text { There is no contract of } \\
\text { supplies of utility water. } \\
\text { There is no contract of } \\
\text { supplies hot-food / ready- } \\
\text { to-cook food. } \\
\text { There is no contract of } \\
\text { fuel deliveries. } \\
\text { There is no contract of } \\
\text { additional } \\
\text { accommodation. } \\
\text { There is no responsible } \\
\text { person for the emergency } \\
\text { supply of the hospital. }\end{array}$ \\
\hline \multicolumn{2}{|c|}{ Hospital 3 - faculty hospital } \\
\hline $\begin{array}{l}\text { Stocks of bottled drinking } \\
\text { water for three days. } \\
\text { Stocks of raw materials } \\
\text { for three days. } \\
\text { Contractual supply of } \\
\text { drinking water. } \\
\text { Contractual supply of } \\
\text { food. } \\
\text { Contractual supply of } \\
\text { medication and blood. } \\
\text { Contractual supply of fuel. } \\
\text { Contractual supply of dry } \\
\text { toilets. } \\
\text { Own kitchen. } \\
\text { Own gas station. } \\
\text { Transfusion station itself. } \\
\text { Online capacities on the } \\
\text { number of patients and } \\
\text { staff. }\end{array}$ & $\begin{array}{l}\text { There is no contractual } \\
\text { supply of drinking water } \\
\text { in the tank from the Fire } \\
\text { Rescue Service. }\end{array}$ \\
\hline
\end{tabular}

\section{Discussion and conclusion}

This paper dealt with the assessment of healthcare facilities from the perspective of their emergency supply. The aim of healthcare facilities is to provide medical care to hospitalized persons. It is also the same at the time of an emergency. Such an extraordinary event may be a power outage. There may also be the crisis, such as floods. These may prevent food or water supplies.

Each healthcare facility provides emergency supplies of energy, food, and water alone. It is clear, therefore, that each healthcare facility has this supply ensured according to its requirements.

A self-assessment method was developed for the evaluation of healthcare facilities. This method is divided into five categories. The aim of this analysis is to determine the availability of emergency medical facilities. The heuristic analysis was used at three hospitals. By the study, one can point to a high diversity regarding their emergency preparedness.

Information systems address emergency or crisis. They are used both at the county level and at the health facility level.

We propose to introduce a new module for these information systems.

This module would be able to assess whether the hospital has enough stock, based on the expected development of an emergency or crisis, to overcome these events. If hospitals are found to need emergency supplies, they are usually required by the contractors. This event is also addressed at the county level. It is also necessary to have feedback here. She would provide the hospital with information on whether and how many supplies are ready and when they are supposed to be delivered. Currently, this situation is solved only by telephone, and very rarely the hospital has feedback.

$$
\text { INPUTS }
$$

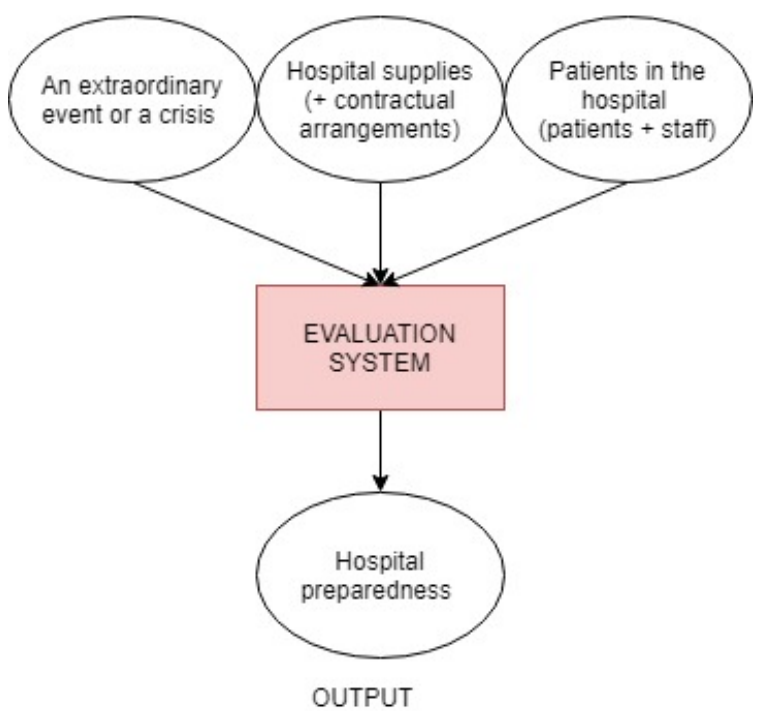

Fig. 4. Module for the crisis management information systems [author].

This paper was supported by the Integral Grant Agency, Tomas Bata University in Zlín IGA/FAI/2018/001 and Department of Security Engineering.

\section{References}

1. A. Sena, C. Corvalan, K. Ebi. Climate change, extreme weather and climate events and health impacts, Global environmental change (2014)

2. V. O. Baker, et al., Teamwork education improves trauma team performance in undergraduate health professional students, J Educ Eval, Health Prof (2015)

3. W. Riley, et al., Didactic and simulation nontechnical skills team training to improve perinatal patient outcomes in a community hospital, Jt Comm Qual Patient Saf (2011) 
4. E. S. Blake, et al., Tropical cyclone report: Hurricane Sandy, Technical report (2012)

5. J. F. McCarthy, D. M. Boyd, Digital backchannels in shared physical spaces: experiences at an academic conference, $\mathrm{CHI}^{\prime} 05$ (2005)

6. V. Fiser, H. Vraspirova, Crisis preparation in education health, SKPZ (2012)

7. Charter of Fundamental Rights and Freedoms Act No. 2/1993, Czech Republic (1999)

8. Measures for Emergency Survival [Internet] Available at: http:/www.hzscr.cz/clanek/opatrenipro-nouzove-preziti-558778.aspx (2014)

9. E. Davoli, Crisis preparedness plan, A practical tool for the preparation of a hospital crisis preparedness plan, with special focus on pandemic influenza (2007)

10. Joint Rescue System Act No. 239/2000, Czech Republic (2017)

11. D. Rehak, L. Folwarczny. The Bases of Technical and Organizational Protection of the Population (2012)

12. Facts about Hurricane Sandy [Internet]. Available at: https://www.dosomething.org/us/facts/11-facts-forhurricane-sandy (2018)

13. I. Umair. Superstrom Sandy May Have Long-Term Public Health Impact [Internet]. Available at: https://www.scientificamerican.com/article/superstor m-sandy-may-have-long-term-public-health-impacts/ (2012)

14. Extreme Wind Strom Catalogue - Kyrill [online]. Available at: http://www.europeanwindstorms.org/cgibin/storms/storms.cgi?storm1=Kyrill (2007)

15. Extreme Winf Storm Catalogue - Dagmar [online]. Available at: http://www.europeanwindstorms.org/cgibin/storms/storms.cgi?storm1=Dagmar_Patrick (2011) 